\title{
Institutional provision of the management of innovative activity and of regional scientific and technological cooperation in the European Union
}

\author{
Aleksei S. Ivanov \\ Volgograd State University, \\ Institute of Management and Regional Economics \\ Chair of Management \\ Volgograd, Russia \\ invanov-volsur@yandex.ru
}

\author{
Tatiana V. Babich \\ Volgograd State University, \\ Institute of Management and Regional Economics \\ Chair of the State and Municipal Administration \\ Volgograd, Russia \\ tat.babich2017@yandex.ru
}

\author{
Daria A. Koneva \\ Volgograd State University, \\ Institute of Management and Regional Economics \\ Chair of the State and Municipal Administration \\ Volgograd, Russia \\ lady.dugina@yandex.ru
}

\begin{abstract}
The article is devoted to the research of the tendencies typical of the institutional provision of the innovation activity management and the regional scientific and technical cooperation in the European Union. The most typical characteristics of the institutional provision of the innovative activity of Europe are studied. They are presented by the necessity of the construction of a multi-level system of the forecasting support for the participants of the innovative process. It was shown that the regional and the sectoral aspects of the institutional provision of the innovative policy and the regional scientific and technological cooperation are closely connected with the encouragement of various forms of the net cooperation among which a specific role in the countries of the European Union is given to the creation of the regional clusters and the nets of the scientific and research cooperation. In the paper the main risks dealing with a fast growth of the number of the enterprises which use cyber physical systems which in their turn have a significant impact on the character of the management of the innovative sphere, on the arising relations and structures are discovered. The authors particularly emphasize the threats of the cyber criminality, prevailing of clearly entrepreneurial tasks over the spirit of research. On the basis of the carried out research the authors make the conclusion about the necessity of taking into account both positive effects (ecological friendliness growth, productivity growth) and the negative ones (sharpening of the cultural conflicts) resulting from an uncontrolled introduction of social innovations. The authors in the end draw the conclusions about a sufficiently systematic character of the European innovative policy which is based on a serious institutional foundation.
\end{abstract}

Keywords - innovation, innovation activity, region, risks, industrial revolution, integration

\section{INTRODUCTION}

The changes taking place in the innovative and technological sphere of Europe have the characteristics common for the world practice and some specificities typical of the European countries. The difference first of all consists in the role of the private sector in the financing of science and innovations, in the role of the venture business, peculiarities of the legal protection of the intellectual property, in the nature and forms of the government regulation. All the factors mentioned above are the reflection of the institutional peculiarities typical specifically of Europe, of both its countries (regions) and the European Union in total. The goal of this paper is to discover the most typical tendencies in the institutional support of the management of the innovative activity and of the regional scientific and technological cooperation with European Union. The goal is also to uncover the main risks connected with the tendencies of the modern industrial revolution.

The main thing what unites the aspiration of the European countries to the innovative breach is a large integration of all innovation forms including those which typically fall out of useful technologies. The program of the European Countries «Horizon 2020» for 2014-2020 includes a considerable increase of the financing of the research and the innovations in the spheres connected with the energy efficiency, climate changes, health of the European population, demographic changes, public services. The declaration of the use of the net forms of the coordination and the integration of the participants of the innovative process makes the convergence of regions and the countries which are initially different upon the innovative potential. Since 2010 the European union actively declares the necessity of the implementation of the 
strategy of the "well targeted specialization" and the realization of the transaction projects. The European commission gives the support for the initiatives of the so called European innovative space in such spheres like productivity and sustainable development of the agriculture, water resources, healthcare in the support of the aging population, "clever" cities and communes [1].

\section{MATERIALS AND METHODS}

The methodological basis of the research is the institutionalism which allows discovering the systematic character of the impact of social and economic institutes on the course of the economic development, technologies, social and business practices. The problems of the innovative and social and technological development of the European regions are analyzed with the use of the elements of the institutional analysis. A wide impact of the tendencies of a new technological revolution on the vectors of the economic, scientific and technological policy in Europe is mediated by a strong impact of the most important social and economic institutions of the European Union. In the paper a high dependence of the modernization of all the spheres of the economic and social life is determined by the historically settled institutes. The communitarian character of the functioning of the institutes of the European innovative development and of the scientific and technological cooperation is shown. Essentially it is spoken about the evolutionary model of the innovative and technological cooperation of the European Union, combining in itself the prognostic support of the modernization with the institutes of the assistance to small and medium-sized businesses and also with the syndicates and with other social institutes. It is emphasized that such a complicated combination of the institutes allows reducing risks connected with the acceleration of the tendencies of a new industrial revolution.

\section{RESULTS AND DISCUSSION}

One of the main key peculiarities of the institutional provision of the innovative policy of Europe is a powerful, multi level system of the forecasting support. The research of the opportunities of the desired development of the society on the basis of the foresight technologies is lead since mid 1970s by a number of the institutes of the European bureaucracy. Already by the end of 1990 s the detailed net structure of the informational and forecasting provision of the Institute for Perspective Technological Research (IPTS) started to form. The European forum in the forecasting activity (EFFLA) suggests the model which has already been used by the Finnish agency in the financing of technologies and innovations which implies the realization of the four basic stages of the forecasting work for the Foresight center of the European commission. The first stage or "strategic informing" (widened foresight) generates the information with the involvement of the participants from the "knowledge" sphere - scientists, qualified specialists. The second stage is the "understanding" of the conscious vision of the analyzed events, creation of the scenarios, trends assessments and it is realized by the European commission. The third stage is the "priorities choice" involves a large range of the informal participants (non governmental, public organizations) however the decision making remains the prerogative of the European Commission and of the European parliament. The fourth stage is the implementation of the solutions, development of the recommendations [2].

The experience of the practical implementation of the model proved to be more interesting in the context of the EU program «Horizon 2020». 80 billion dollars from the budget funds is expected to be spent. This program is focused on the achievement of the industrial leadership of Europe, on the solution of a number of social problems. The strategy is founded on such forces of the future changes like globalization, demography, ecology, biosphere, migration, urbanization, lack of resources and of energy, digital revolution, biotechnology and breakthrough in medicine, work, professional skills and intellect, individual needs, aspirations and development of the opportunities for satisfaction. These drivers in their turn allowed for this moment to isolate four prospects for the EU development: innovations and competitive ability; sustainable development; prospects for social shifts; spheres for cardinal innovative breakthroughs. In total 15 scenarios have been suggested which created the informational base for the creation of the strategic decisions important for the EU. As V.S. Tsirenshchikov notices "the prognostic provision (foresight) became in the EU one of the most important priorities of the conceptual formation and the implementation of the measures in the creation of the innovative development. The improvement of the forecasting in the communitarian level is made in the direction of its institutionalization with the creation of the net structures, of the integrated and system development, of the unification of the realization methods" [3].

Within the frame of the management of the innovative activity of the EU a number of frame programs in science and technologies are taken. The main idea of them became the integration of the space of the origin and the development of the scientific knowledge and as a result the creation of the European scientific and research space. The regional and sectoral aspects of the institutional provision of the management of the scientific, technological and innovative activity are closely related to the encouragement of various net forms of the cooperation. They are manifested in the creation of the regional cluster and the nets of the industrial, scientific and research cooperation (for instance, the creation of the European creative and industrial alliances, intergovernmental cooperation of the European countries in the industrial development, of the standards, of the security of the cyberphysical industrial systems) and also in the creation of the economic zones favouring the innovative activity and the foreign investments in this sphere (credit against tax in Ireland for the encouragement of the transnational high technological business for the creation of the affiliates of their productions in the country). The following strategies of the regional specialization are implemented in the EU. They are "Industry 4.0" in Germany, «SmartFactory» in Netherlands, «AllianceIndustrieduFutur» in France, «MadeDifferent» in Belgium etc. Within the strategy of «Industry 4.0» the development of the efficient forms of the informative and financial support of the participants of the innovative market are developed. 
It is worth mentioning the growing tendency during the latest years of the return into the European regions of the enterprises as the response to the threats of the loss of the technological leadership, of the industrial culture, of the rupture of the traditionally close relations of the applied science and industry. The reduction of the share of the processing industry as the most active consumer of all technological innovations influenced mainly the developed countries. For instance in Great Britain, in France the share of the processing industry in the GDP during the period 19602012 reduced more than twofold. Among the European countries only Germany held the status of the powerful industrial nation having conserved the value of this index by 2012 at the level of $20 \%$ of the GDP. At the same time during the latest years the tendency of the return of the processing industries back into the countries of origin is observed. The return of the enterprises creating the additional value back into the country of origin or the reshoring is seen as a process capable not only of recovering the leading positions of the processing industries but also is considered as a way of increasing the opportunities of the integration of the enterprises, organizations generating new knowledge and technologies and also mastering them. This circumstance gives the opportunity to create new spaces for the scientific and technological leadership in the territory of the European Union itself, to encourage the creation of a powerful intellectual capital, the opening of new technology intensive working places within the frame of the European integration. Naturally under the modern conditions of the development of the transnational business, of the openness to the flow of the intellectual capital, of the information between the countries the success of the companies is closely connected with the creation of global nets and clusters. However regional scientific and technological policy implies the aspiration to the localization of the most efficient operations in its territory. In some European countries it provides high values of numerous macroeconomic indices. Only in Great Britain the reshoring can increase the GDP by 6-12 billion pounds and can create from 100 to 200 thousand new working places by mid 2020s. In that connection it concerns not only the production itself but also the sphere connected with its infrastructural servicing, $\mathrm{R} \& \mathrm{D}$, telecommunications and so on [4].

A similar strategy has the support from the institutes of the economic policy of the EU in particular in the strategy "Renaissance of the industry within the frame of the strategy of the Sustainable development of Europe" supported by the European Parliament. The share of the processing industry in the Gross national product of the EU is expected to amount to $20 \%$. The conception of the new industrialization which is actively implemented in the USA, Canada, in the Western countries is based on the one hand on the reshoring trend and on the other it is founded on their transfer on the new robotic and technologicical base. It started creating already in 1970 s and it is connected with the micro processing revolution. The automation and the computerization of the industrial forces changes the scenery of social systems and also it changes the role and the structure of labour. It is thought that the transfer of the industrial policy of the modern Europe to a new industrialization is impossible without considerable organizational changes at national, supranational, corporative level of the regulation, of the social control. Some of the institutes of such a regulation are being created for the moment as if responding to the technological challenges and to the business interests, some of them are the result of long term historical process of the evolution of social institutes and models of the interaction between the business and the society, between the state and the corporations. The balance between the old and new institutes is a precondition of a stable development, indispensable requirement without which it is impossible to achieve the harmony of the innovative changes, to create their painless and productive adoption by the culture of the society. It is worth emphasizing that in the management of the regional and interregional scientific and technological cooperation there exist traditional models and projects of the EU such as IncoNet EECA, frame programs of the transborder cooperation, partnership and so in and they are maintained by the historically established institutes (often national ones) and the practice of the development of which has a potential for the cooperation. Thus in Germany a special attention is paid to the support of the Mittelstand or of small and medium-sized manufacturing enterprises (arising basically on the basis of the family business) where about 500 persons work and which create a significant innovative potential used also by large scale industrial business. About 15,5 million people (or about $38 \%$ of the employed people) work in such companies (Mittelstand). This circumstance permitted the German economy to overcome the consequences of the crisis of 2008. Some firms use the scheme of the cooperation with the researcher from various universities and scientific centers, other firms create on their base the laboratories and the research centers. The important role has a large scale cooperation of such firms with the students of the German universities when the model of the "double education" is implemented which allows assuring the professional adaptation, practical adaptation of new technologies and allows reducing unemployment risks among the young people. The cooperation of these enterprises (Mittelstand) with large concerns as subcontractors made them the most successful firms. The investments of Mittelstand into the research and development are significant. According to the data of the Federal Ministry for Economics and Technology of Germany from 2004 to 2010 the growth of the expenses for R\&D amounted to $71 \%$ (for large scale business it made up 19 $\%$ ); in 2008-2010 54\% of the companies of the German Mittelstand entered the markets with product and processing innovations [5].

A quick growth of the number of the enterprises which use cyberphysical systems attracts the attention of the authorities, business, syndicates what is especially important in case of the assessment of possible risks of the unemployment growth or other problems in the labour market. In this respect it is worth emphasizing a considerable role of the syndicate self organization typical of the regions of the continental Europe. This fact considerably influences the character of the innovative policy, arising relations and structures. For instance it is the inclusion of the strategy «Industry 4.0» into the union «Future of the Industry» of the Federal association of the employers, of the syndicate of the IGMetall, of the sectoral professional syndicates [6]. 
It is worth enumerating the main risks to which the arising institutional system is expected to react within the innovative and technological policy. The Europe confronts the goal of the solution of the energetic, ecological, demographic, migration problems, unemployment challenges and labour mobility. It is indispensable to insure the risks connected with the introduction of new bio technologies, cyberphysical systems in the industry, technology of augmented reality, hyper connectedness on the basis of the nets, cognitive computerization. The problems set before the social structures, syndicates are principally new goals connected not only with the overcoming of the unemployment programs, with the search of the structural reforms in traditional industries or in a typical encouragement of the labour force mobility but there are also new conditions of the technological unification and of the competitive fight in quickly arising and quickly disappearing business structures. Besides the threats of the cyber criminality are also high. The growing pragmatism of the science, the decay of the scientific spirit against purely entrepreneurial tasks raises fears [7]. It is supposed that the overactive, often uncontrolled introduction of social innovations, expansion of the non commercial forms of the innovations is capable of causing serious societal changes. They can have both positive effects (ecological friendliness, productivity growth) and the negative ones which strengthen at the back of a negative social convergence of the countries of the recent decades, of the sharpening of the cultural conflicts under the conditions of the devaluation of traditional cultural, educational structures and the institutes of the modern world. The considerable risks are presented by a strengthening of the bureaucratic load in the system of the coordination and the social and technological cooperation. In this respect these are usually powerful traditions and institutes of Europe which can be responsible for possible negative tendencies of innovative and technological changes.

\section{CONCLUSION}

In the conclusion it can be mentioned that the management of the innovative activity in the EU constructed on a considerably powerful institutional foundation is quite systematic. The isolation of the whole complex of the arising problems is only possible under the condition of the implementation of the principles of the transparency, integrity of scientific, educational, cultural, industrial and specifically innovative policy, on the creation of the pluralism of social, cultural forms of the economic sphere, technological and business modes of various regions and countries of Europe. The community character of the institutes, activity measures of a number of the participants of the research, educational and industrial spheres provides the unification and together with that the maximal coverage of all the interested parties.

\section{References}

[1] Tsirenshchikov V.S. Evrosoyuz: novoe v innovatsionnom stroitel'stve [The European Union: what's new in the innovative construction]. Sovremennaya Evropa [Modern Europe], 2016, №1, pp.107-121.

[2] Tsirenshchikov V.S. Evrosoyuz: prognosticheskaya podderzhka innovatsii [The European Union: a predictive innovation support]. Moscow: Institute of Europe RAS, 2017, p.22.

[3] Tsirenshchikov V.S. Evrosoyuz: prognosticheskaya podderzhka innovatsii [The European Union: a predictive innovation support]. Moscow: Institute of Europe RAS, 2017, p.58.

[4] Reshoring - A New Direction for the UK Economy. PricewaterhouseCoopers - PWC, 2014, London, pp. 25-34.

[5] German Mittelstand: Engine of the German economy. Available at: https://www.deginvest.de/DEG-Documents-in-English/AboutDEG/Events-and-Awards/BMWi_Study_German-Mittelstand.pdf. Date of reference 17.01.2018.

[6] Belov V.B. Novaya paradigma promyshlennogo razvitiya Germanii strategiya «Industriya 4.0» [The new paradigm of industrial development of Germany - strategy "industry 4.0"]. Sovremennaya Evropa [Modern Europe], 2016, №1, p.17.

[7] Vodopyanova E.V. Evropa v poiskakh innovatsii (razmyshleniya filosofa) [Europe in search of innovations (reflections of a philosopher)]. Sovremennaya Evropa [Modern Europe], 2014, №2, p.33. 